\title{
Area summation is related to efficient neural representation
}

\author{
Fariba Sharifian ${ }^{1,2,3,4^{*}}$, Hanna Heikkinen ${ }^{1,2}$, Ricardo Vigário ${ }^{5}$, Simo Vanni ${ }^{3,4}$ \\ From 24th Annual Computational Neuroscience Meeting: CNS*2015 \\ Prague, Czech Republic. 18-23 July 2015
}

In the primary visual cortex (V1), increasing stimulus size first increases and then decreases the neural firing rate before reaching an asymptote [1,2]. This typical response curve, area summation function (ASF), defines canonical contextual modulation in typical V1 neuron. Previous studies suggest that contextual modulation associates with efficiency of the neural network $[3,4]$. Here, we studied the relationship between ASF and efficiency of system level neural activation patterns.

Cavanaugh et al. [1] provided quantitative data from macaque cortex, as well as a mathematical description for the ASF. Therefore, we created a theoretical expected cortical response for an arbitrary gray-level image input stimulus based on ASF. Next, we used a biophysically meaningful (biomimetic) network of exponential integrateand-fire neurons to stimulate V1 response (Heikkinen,
Sharifian, Vigario and Vanni, unpublished observations). As an outcome, we compared the distance between the biomimetic simulator outputs to the expected ASF function (Distance to Area Summation, DAS). Finally, we studied entropy per spike, energy consumption and neural population sparseness as a function of the DAS for 20 natural grayscale images. In the biomimetic simulation we left V1-extrastriate and V1 excitatory-inhibitory connection strengths as free parameters in the simulations. A square search with 626 combinations of values was run for all the 20 natural stimuli resulting in $20 * 626=12520$ simulated response patterns.

Our results show that: i) there is a clear association between the entropy per spike and DAS (distance correlation $=0.66$, Fig 1.a). ii) A negative link exists between the level of energy consumption (linearly associated with

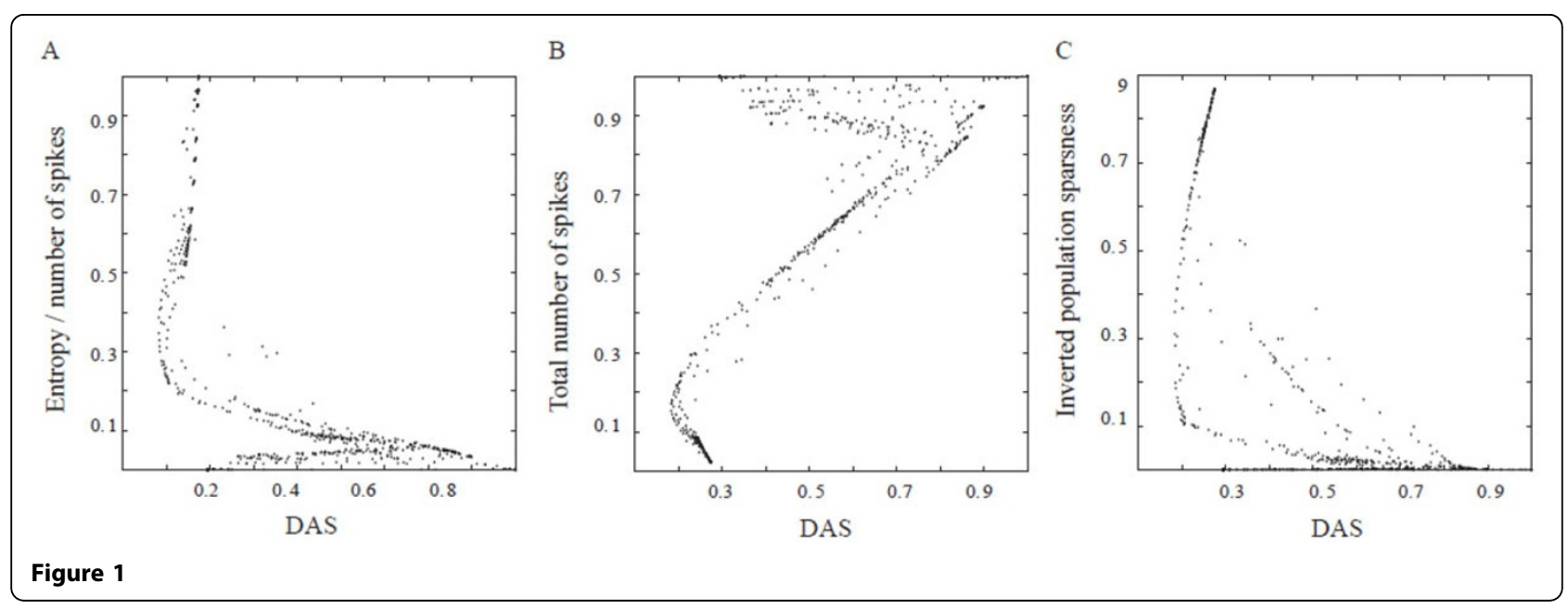

\footnotetext{
* Correspondence: fariba@neuro.hut.fi

'Brain Research Unit, Department of Neuroscience and Biomedical

Engineering, Aalto University, Espoo, Finland

Full list of author information is available at the end of the article
}

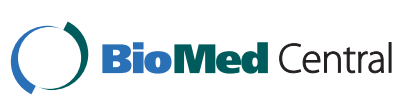

(c) 2015 Sharifian et al. This is an Open Access article distributed under the terms of the Creative Commons Attribution License (http:// creativecommons.org/licenses/by/4.0), which permits unrestricted use, distribution, and reproduction in any medium, provided the original work is properly cited. The Creative Commons Public Domain Dedication waiver (http://creativecommons.org/publicdomain/ zero/1.0/) applies to the data made available in this article, unless otherwise stated. 
spike frequency) in modeled output patterns and DAS $(\mathrm{r}=0.62, \mathrm{p}<0.001$, Fig 1.b). iii) Population sparseness of the modeled output patterns is positively related to the DAS ( $r=0.60, p<0.001$, Fig 1.c).

In conclusion, the results of our study suggest that there is a link between area summation function and efficient information coding in the cortical visual system.

\section{Authors' details}

'Brain Research Unit, Department of Neuroscience and Biomedical Engineering, Aalto University, Espoo, Finland. ${ }^{2} \mathrm{AMI}$ Centre, Aalto Neuroimaging, Aalto University, Espoo, Finland. ${ }^{3}$ Clinical Neurosciences, Neurology, University of Helsinki, Helsinki, Finland. ${ }^{4}$ Helsinki University Hospital, Helsinki, Finland. ${ }^{5}$ Department of Information and Computer Science, Aalto University School of Science, Aalto University, Espoo, Finland.

Published: 18 December 2015

\section{References}

1. Cavanaugh JR, Bair W, Movshon JA: Nature and interaction of signals from the receptive field center and surround in macaque V1 neurons. Journal of Neurophysiology 2002, 88(5):2530-2546.

2. Angelucci A, Levitt JB, Walton EJ, Hupe JM, Bullier J, Lund JS: Circuits for local and global signal integration in primary visual cortex. Journal of Neuroscience 2002, 22(19):8633-8646.

3. Sharifian F, Nurminen L, Vanni S: Visual interactions conform to pattern decorrelation in multiple cortical areas. Plos One 2013, 8(7):e68046.

4. Vanni S: Local model for contextual modulation in the cerebral cortex. Neural Networks 2012, 25:30.

doi:10.1186/1471-2202-16-S1-P71

Cite this article as: Sharifian et al: Area summation is related to efficient neural representation. BMC Neuroscience 2015 16(Suppl 1):P71.

\section{Submit your next manuscript to BioMed Central} and take full advantage of:

- Convenient online submission

- Thorough peer review

- No space constraints or color figure charges

- Immediate publication on acceptance

- Inclusion in PubMed, CAS, Scopus and Google Scholar

- Research which is freely available for redistribution

Submit your manuscript at www.biomedcentral.com/submit
C Biomed Central 